\title{
Interactions Between Coniothyrium minitans and Sclerotinia minor Affect Biocontrol Efficacy of $C$. minitans
}

\author{
P. Chitrampalam, B. M. Wu, S. T. Koike, and K. V. Subbarao
}

First, second, and fourth authors: Department of Plant Pathology, University of California, Davis, c/o United States Agricultural Research Station, Salinas, CA 93905; and third author: University of California Cooperative Extension, 1432 Abbott Street, Salinas 93901. Current address of B. M. Wu: Department of Botany and Plant Pathology, Oregon State University, Madras 97741. Accepted for publication 2 October 2010.

\begin{abstract}
Chitrampalam, P., Wu, B. M., Koike, S. T., and Subbarao, K. V. 2011. Interactions between Coniothyrium minitans and Sclerotinia minor affect biocontrol efficacy of C. minitans. Phytopathology 101:358-366.

Coniothyrium minitans, marketed as Contans, has become a standard management tool against Sclerotinia sclerotiorum in a variety of crops, including winter lettuce. However, it has been ineffective against lettuce drop caused by $S$. minor. The interactions between $C$. minitans and $S$ minor were investigated to determine the most susceptible stage in culture to attack by $C$. minitans, and to determine its consistency on $S$ minor isolates belonging to four major mycelial compatibility groups (MCGs). Four isolates of $S$. minor MCG 1 and 5 each from MCGs 2 and 3 and one from MCG 4 were treated in culture at purely mycelial, a few immature sclerotial, and fully mature sclerotial phases with a conidial suspension of $C$. minitans. Sclerotia from all treatments were harvested after 4 weeks, air dried, weighed, and plated on potato dextrose agar for recovery of $C$.

minitans. S. minor formed the fewest sclerotia in plates that received $C$. minitans at the mycelial stage; $C$. minitans was recovered from nearly all sclerotia from this treatment and sclerotial mortality was total. However, the response of MCGs was inconsistent and variable. Field experiments to determine the efficacy of $C$. minitans relative to the registered fungicide, Endura, on lettuce drop incidence and soil inoculum dynamics were conducted from 2006 to 2009. All Contans treatments had significantly lower numbers of sclerotia than Endura and unsprayed control treatments, and drop incidence was as low as in Endura-treated plots $(P>0.05)$. Although the lower levels of lettuce drop in Contans treatments were correlated with significantly lower levels of sclerotia, the lower levels of lettuce drop, despite the presence of higher inoculum in the Endura treatment, was attributable to the prevention of infection by S. minor. A useful approach to sustained lettuce drop management is to employ Contans to lower the number of sclerotia in soil and to apply Endura to prevent $S$. minor infection within a cropping season.
\end{abstract}

Lettuce (Lactuca sativa L.) is one of the most important coolseason vegetable crops grown in coastal California, and the state accounts for $>73 \%$ of U.S lettuce production (5). Lettuce production occurs year-round in coastal valleys of California and is only interrupted by the mandatory "lettuce-free" period to manage Lettuce mosaic virus. Winter production of lettuce occurs in the inland and desert regions of California (36). Lettuce drop is one of the most economically important diseases of lettuce $(17,32,44)$ and can result in yield losses of $\leq 75 \%$ (35). Lettuce drop is caused by both Sclerotinia sclerotiorum (Lib.) de Bary and $S$. minor Jagger. In coastal California, the disease is predominantly caused by $S$. minor. $S$. minor produces large numbers of small sclerotia on diseased lettuce, which function as both survival propagules and primary inoculum for subsequent lettuce crops $(16,23)$. Although sclerotia of $S$. minor are capable of producing apothecia under laboratory conditions, apothecia and ascospore infection of lettuce under field conditions have not been observed (37).

Currently, commercial lettuce cultivars with resistance to $S$. minor are unavailable (19). Crop rotation with nonhost broccoli significantly reduces both sclerotium density of $S$. minor and lettuce drop incidence (18). However, rotation with broccoli or fallowing land for even brief periods in coastal California is often not economically feasible. Therefore, lettuce drop management over the years has relied on the post-thinning application of fungicides. Even with the application of fungicides, however,

Corresponding author: K. V. Subbarao; E-mail address: kvsubbarao@ucdavis.edu

doi:10.1094/PHYTO-06-10-0170

(c) 2011 The American Phytopathological Society losses of 5 to $40 \%$ have been reported $(9,29,30,37)$ owing to potential rapid degradation of fungicides in soil (27). Currently, the lone fungicide that has remained effective against $S$. minor is boscalid (Endura; BASF Corporation, Research Triangle Park, NC) (30). In recent years, however, control failures with Endura have been observed but are not due to the development of resistance in S. minor populations (K. V. Subbarao, unpublished data).

Biocontrol has long been evaluated as a management option against Sclerotinia spp. in many cropping systems $(9,11,20$, 21,24,28,31). Trichoderma spp., Sporidesmium sclerotivorum, and Coniothyrium minitans are the fungal species most widely tested against Sclerotinia spp. (2,6-8,10,20,24,26,33,36,37). Evaluation of different biological control treatments against lettuce drop caused by both Sclerotinia sclerotiorum and S. minor revealed that none of the three treatments were effective against $S$. minor. However, $C$. minitans was highly effective against $S$. sclerotiorum on lettuce (9), as had been previously determined on other crops $(21,28)$.

C. minitans is an obligate mycoparasite that attacks only the sclerotia of ascomycetous fungi, including S. sclerotiorum, $S$. minor, S. trifoliorum, and Stromatinia cepivora, but not the sclerotia of basidiomycetous fungi (43). The reasons for this selectivity of $C$. minitans to sclerotia of ascomycetous fungi are not known. In addition, the information on molecular interaction between $C$. minitans and Sclerotinia sclerotiorum is very limited. C. minitans hyphae penetrate sclerotia through the outer pigmented rind intercellularly or via existing cracks in the sclerotial surface. The outer melanized rind layer is more resistant to invasion than the unpigmented middle cortical and inner medullary tissues. Therefore, the penetration of the outer rind is achieved mainly through enzymatic degradation (22) and also by physical 
pressure (34). Cell-wall-degrading enzymes such as glucanase and chitinase are believed to play a role in cell wall penetration, and the exo- $\beta-1-3$ glucanase gene is highly expressed in $C$. minitans during the parasitic interaction with $S$. sclerotiorum (13).

Although both Sclerotinia spp. are closely related, the reasons for the ineffectiveness of $C$. minitans against $S$. minor are unclear. $S$. minor produces large number of small sclerotia (37) on the infected lettuce, and one sclerotium within the competence volume of soil (15) is sufficient to cause disease. Potentially, the recommended rate of $C$. minitans $(2.2 \mathrm{~kg} / \mathrm{ha})$ may not be sufficient to parasitize and destroy the large number of small sclerotia in soil. Furthermore, the optimum times for the application of $C$. minitans against $S$. minor to expand its efficacy or the stages in the pathogen biological cycle most susceptible to environmental stresses and attacks by other organisms are unknown. Such information can be used to time the application in the field to increase the parasitic destruction of sclerotia by $C$. minitans which, in turn, would reduce inoculum augmentation of the soil after a susceptible crop. S. minor is also highly diverse in the Salinas Valley, with the population comprising many mycelial compatibility groups (MCGs). Of these, four MCGs occur in greater frequency than others (45). Whether $C$. minitans has equal efficacy on strains from the dominant MCGs is also unknown, and such knowledge is imperative for successful management of lettuce drop caused by $S$. minor using $C$. minitans.

The specific objectives of this study were to (i) determine the most susceptible growth phases in the life cycle of $S$. minor to $C$. minitans, (ii) evaluate $C$. minitans against different MCGs of $S$. minor, and (iii) determine the effects of $C$. minitans on sclerotial population of $S$. minor and incidence of lettuce drop over multiple crop seasons in the field.

\section{MATERIALS AND METHODS}

Laboratory experiments. Experiments were conducted to determine the most susceptible growth phase in $S$. minor to $C$. minitans parasitism and to test the efficacy of $C$. minitans on different MCGs of $S$. minor. Five $S$. minor isolates each were randomly chosen from MCGs 1, 2, and 3 and one isolate from MCG 4 because only few isolates were in this group (46) and only one was revived from storage. One of the five isolates chosen from MCG 1 produced sclerotia inconsistently; therefore, it was later excluded from this study. The three growth phases in $S$. minor culture tested for the susceptibility to $C$. minitans parasitism were (i) mycelial phase before initiation or formation of sclerotia (4th day of incubation), (ii) early sclerotial formation phase when sclerotia were not fully melanized (6th day of incubation); and (iii) sclerotial maturation phase (15th day of incubation). A mycelial plug of each isolate of $S$. minor obtained from 4-day-old cultures on potato dextrose agar (PDA) was placed separately in the center of PDA plates and incubated at $20^{\circ} \mathrm{C}$ in the dark for either 4,6 , or 15 days depending upon the treatments. A $1-\mathrm{ml}$ conidial suspension of $C$. minitans prepared from a 14-day-old culture on PDA was uniformly dispensed manually using a sterilized spreader into each 4-, 6-, or 15-dayold culture of $S$. minor $\left(2 \times 10^{7}\right.$ conidia $/ \mathrm{ml}$; conidial density determined using a hemacytometer). Plates receiving $1 \mathrm{ml}$ of sterilized water served as nontreated controls. Each treatment was replicated three times and the experiment was conducted twice. Plates were incubated at $20^{\circ} \mathrm{C}$ for 14 days following the treatment with $C$. minitans. Two sets of observations were taken from each treatment. (i) Sclerotial mortality: five sclerotia from each plate were randomly picked and surface sterilized with $70 \%$ ethanol for $1 \mathrm{~min}$, rinsed twice with sterilized water, and placed individually on PDA agar plugs $(1 \mathrm{~cm}$ in diameter) amended with streptomycin sulfate and incubated at $20^{\circ} \mathrm{C}$ for a week. Data on the number of germinated sclerotia with and without $C$. minitans infection and dead sclerotia were taken. (ii) Sclerotial dry weight: sclerotia from each plate were collected separately, air dried for $\approx 36 \mathrm{~h}$ in a laminar flow hood, and weighed.

Statistical analysis of the data from laboratory experiments. Analysis of variance (ANOVA) was performed on effects of treatment (application of conidial suspension of $C$. minitans to the three phases of $S$. minor culture) and MCG of isolates on dry weight of sclerotia in SAS (SAS Institute Inc., Cary, NC) using a mixed model procedure. Because a significant interaction of time-MCG-treatments was detected, data from each treatment time were analyzed separately using a general linear models procedure. Similar analyses were also performed on the effects of treatment time, MCG of isolate, and their interaction on sclerotial mortality.

Field experiments. Field experiments were conducted at the United States Department of Agriculture-Agricultural Research Station in Salinas, CA in 2006 to 2009 to evaluate the efficacy of a commercially available $C$. minitans formulation on the numbers of sclerotia of $S$. minor in soil and subsequent lettuce drop incidence. The soil was classified as an Antioch fine sandy loam (fine, smectitic, thermic typic natrixeralf), with a mean particle size distribution of $45 \%$ sand, $32 \%$ silt, and $23 \%$ clay, a $\mathrm{pH}\left(\mathrm{H}_{2} \mathrm{O}\right)$ of 6.9 , and an organic matter content of $2.2 \%$. This sandy loam soil was selected because it is the prevalent soil type on which lettuce is produced in coastal California. Because the site had been used for experiments with $S$. sclerotiorum during previous years, it was fumigated with Tri-Con 57/43 Methyl-Bromide/ Chloropicrin (Trical Inc., Hollister, CA) at $420 \mathrm{~kg} \mathrm{ha}^{-1}$ prior to all experiments to eliminate any residual inoculum. The treatments were then arranged in a randomized complete block design with four replications. Blocks were separated by a 2-m strip of bare soil to prevent plot interactions. Each treatment consisted of eight beds of $8 \mathrm{~m}$ in length.

To establish uniform inoculum densities in all treatments, field soil was infested with sclerotia produced from $S$. minor isolates (BM001, BM005, BM007, and BM010) originally isolated from infected lettuce in commercial fields in Salinas, CA. To produce sclerotia for this field experiment, fresh Russet Burbank potato tubers were washed, peeled, and cut into 1.5 -by- $1.5-\mathrm{cm}^{2}$ pieces. Then, $\approx 250 \mathrm{~g}$ of potato pieces were placed into 500-ml flasks, sealed with foil, autoclaved for $30 \mathrm{~min}$, and reautoclaved for 30 min $24 \mathrm{~h}$ later. After the potato pieces cooled down to room temperature, three to four agar plugs $(0.5 \mathrm{~cm}$ in diameter) cut out of $S$. minor cultures were transferred into each flask. The flasks were incubated at 23 to $24^{\circ} \mathrm{C}$ and periodically shaken to promote uniform colonization of potato pieces. Then, $\approx 6$ weeks later, sclerotia were collected by washing flask contents through a fine mesh sieve and straining out the sclerotia. Sclerotia were then air dried and stored at room temperature until used. Sclerotia were dispersed into the seed rows using an EarthWay Precision Seeder (EarthWay Products, Inc., Bristol, IN) at a rate of $\approx 500$ sclerotia/m (determined by counting the number of sclerotia dispersed by the seeder in a linear meter). The subsequent seasons used the residual inoculum (sclerotia) in the soil augmented by infected plants within each treatment.

Commercial crop production practices were implemented (25). Prior to each lettuce planting, the field was disked, rolled, subsoiled, and leveled. The field was then preirrigated with $\approx 50 \mathrm{~mm}$ of water to prepare the soil for seedbed formation. To prepare the seedbeds, a rolling cultivator passed two times over the field, followed by a bed shaper and fertilizer applicator. Beds were $1 \mathrm{~m}$ wide and received preplant fertilizer (6:20:20, N-P-K) at $336 \mathrm{~kg}$ $\mathrm{ha}^{-1}$. During the entire study, crisphead lettuce cv. Salinas was direct-seeded in April (spring season) and July (fall season) using a four-bed precision planter. This planter plants two rows of lettuce on 1-m-wide beds at 5-cm spacing between plants within a row. The planted field was sprinkler irrigated frequently for $\approx 10$ days until seedlings were established and twice weekly throughout the season to promote infection by $S$. minor. Three 
weeks after emergence, lettuce seedlings were manually thinned to a final spacing of $30 \mathrm{~cm}$. Plots were side-dressed with fertilizer twice during each season. The first fertilizer side-dress (15:8:4, $\mathrm{N}-\mathrm{P}-\mathrm{K}$ at $336 \mathrm{~kg} \mathrm{ha}^{-1}$ ) was applied immediately after thinning, and the second side-dress was applied 3 weeks after thinning (urea-ammonium nitrate, 32:0:0, N-P-K, at $327 \mathrm{~kg} \mathrm{ha}^{-1}$ ).

Treatments tested in the field in 2006 to 2007 were (i) C. minitans (Contans [Wettable Granule]; Prophyta, Inc., Germany) at $2.2 \mathrm{~kg} / \mathrm{ha}$ applied three times (1 week prior to and 1 week following thinning and, finally, on the crop residue following harvest but prior to disking), (ii) C. minitans at $4.4 \mathrm{~kg} / \mathrm{ha}$ applied three times as in the previous treatment, and (iii) Endura at $0.57 \mathrm{~kg}$ a.i./ha applied at post thinning and 1 week following the first application. Two additional treatments involving Contans were included in 2008 to 2009; application of Contans at $2.2 \mathrm{~kg} / \mathrm{ha}$ at thinning and at post-harvest on the crop residue, and Contans at $2.2 \mathrm{~kg} / \mathrm{ha}$ applied once on the crop residue prior to disking. The plots were monitored weekly for lettuce drop incidence by counting the number of diseased lettuce plants until market maturity. Disease incidence was calculated as the ratio of the number of diseased plants to the total number of lettuce plants in the middle four beds of each plot and expressed as a percentage.

Soil sampling. To test the effects of different treatments on the numbers of sclerotia in soil, soil samples were collected from the top 10-cm soil layer at three random spots in the middle four beds of each plot prior to thinning during each cropping season. The soil collected from within a bed was bulked to provide a total volume of $500 \mathrm{~cm}^{3}$ of soil. A $100-\mathrm{cm}^{3}$ aliquot of each soil sample from each bed was assayed separately for sclerotia by wet sieving (38) and the data from the four beds within each plot were combined and averaged to provide the total number of sclerotia per plot.

Analyses of data from field experiments. $S$. minor infects lettuce with mycelium from direct germination of sclerotia, and additional infections of the same plant do not occur during a season; therefore, lettuce drop caused by $S$. minor is considered a monocyclic disease. The disease progress curve for monocyclic disease is best described by a monomolecular model. Therefore, a monomolecular growth model denoted as incidence $=100 \times(1-$ $e^{-r w+c}$ ) was fitted to the disease (incidence) progress curve for each treatment and cropping seasons by using nonlinear regression in SAS. Two parameters, $r$ (epidemic speed) and $c$ (related to the time from the first disease reading to the first disease incidence increase), were estimated for each treatment and compared among treatments. A paired $t$ test was performed to compare the fitted parameters for the fall and spring seasons. ANOVA was performed using a mixed model to test the effects of fixed factors, including year, season, and treatment, on the final incidence of lettuce drop and sclerotial population over the entire study period (SAS Institute Inc.). Because interactions of year-season-treatment were significant, data from each season were analyzed separately using a general linear models procedure because of the simple experimental design. Means were compared among treatments using the least significant difference test. The relationship between disease incidence in each crop and the sclerotial density measured in the subsequent crop was analyzed. Because the time from the harvest of a crop to soil sampling for determining sclerotium density in the subsequent crop was different, data for spring and fall seasons were analyzed separately using linear regression in SAS (SAS Institute Inc.). The residual (the observed sclerotium density - the predicted sclerotium density based on incidence) was calculated for each combination of crop-treatment-replication. Then, ANOVA and comparison of means were performed on the effects of fixed factors as described for incidence and sclerotial population. Similarly, the relationship between the sclerotium density within a season and the final lettuce drop incidence during the season was also analyzed. For this analysis, a monomolecular model, incidence $=100-100 \times$ $e^{-b \times s c}$, was used to fit the curve, where $s c$ is the sclerotium density and $b$ is the parameter estimated by the model. Because the two treatments (Contans at harvest and Contans at thinning and harvest) were not included at the beginning of this study, they were excluded from these two analyses.

\section{RESULTS}

Interactions between $C$. minitans and different growth phases and MCGs of $\boldsymbol{S}$. minor. ANOVA using a mixed model revealed that $C$. minitans significantly reduced $(P<0.0001)$ sclerotial production at all three growth phases of $S$. minor tested in all four MCGs, and the mycelial phase of $S$. minor is the phase most sensitive to $C$. minitans (data not shown). However, effects of MCG and its interaction with the time of introduction of $C$. minitans into $S$. minor cultures were significant, suggesting that the effects of $C$. minitans treatment vary with MCGs of $S$. minor (data not shown). MCG 1, the most predominant MCG in the $S$. minor population from the Salinas Valley, tended to be most sensitive to $C$. minitans (Fig. 1). Regardless of MCGs, $S$. minor was least sensitive when mature sclerotia had already formed in cultures (Fig. 1).

Similarly, ANOVA on sclerotial mortality data also revealed significant differences among both MCGs and timing of $C$. minitans introduction $(P<0.0001)$ into $S$. minor cultures. Unlike the dry weight of sclerotia, no significant interaction between the time of $C$. minitans introduction into cultures and MCG $(P=$ 0.5791 ) was detected. Percent sclerotial mortality decreased with increased age of $S$. minor cultures, and inoculation of $C$. minitans at the mycelial phase of $S$. minor resulted in significantly higher percent sclerotial mortality than at either the sclerotial formation or maturation phases (Fig. 2). The results also revealed that $C$. minitans had significantly different effects on isolates belonging to different MCGs. The percent sclerotial mortality for isolates in MCG 4 was significantly higher than isolates in other MCGs at all three phases tested. The percent sclerotial mortality in MCG 1 after $C$. minitans treatment was also significantly higher than that in MCG 2 and MCG 3 in all phases but comparable with (in mycelial phase) or lower than (in other two phases) that in MCG 4. MCGs 2 and 3 were the least sensitive to $C$. minitans (Fig. 2).

Disease progress. The disease (incidence of lettuce drop) progress curves followed a monomolecular growth model for all cropping seasons and treatments. Lettuce drop occurred in all seven seasons during the study, and the final incidence at harvest was 8 to $85 \%$ in the unsprayed control (Figs. 3 and 4). In all seasons except during fall 2006, parameter $c$ (related to the time from the first disease reading to the first disease incidence increase) was 0.644 to 0.950 . Lettuce drop normally appeared 3 to 4 weeks prior to the end of each season, with parameter $c$ at 1.31 to 2.349. The paired $t$ tests ( $c$ parameters in spring and fall were paired according to treatment) showed that the epidemic in the fall, measured as weeks from the first disease reading date, occurred significantly earlier than in the spring in 2008 and 2009 but not in 2007. Once lettuce drop appeared, the disease incidence progressively increased each week and the speed of the disease epidemic was highest in 2006, the only season the soil was inoculated with sclerotia. Paired $t$ tests also demonstrated that the epidemic speed was significantly higher in the fall than in the spring in 2007 to 2009 . The effects of different treatments were mainly on parameter $r$, the epidemic speed. Beginning in spring 2007, the epidemic speed was significantly lower in plots treated with Endura and Contans than in untreated control plots, except during spring 2008, when the two new Contans treatments were introduced for the first time.

Effect of Contans and Endura on final disease incidence and sclerotial population of $\boldsymbol{S}$. minor. Results from ANOVA demonstrated that the effects of year, season, and treatment, as well as interactions of treatment-year and year-season, were 
significant (Table 1). Analyzed separately for each crop, the effect of treatment was not statistically significant during fall 2006, when all plots was uniformly inoculated, and the difference among treatments was significant for almost all other crops (Table 2). Final incidence of lettuce drop regardless of treatments decreased over years but slightly increased from spring crop to fall crop within the same year. Specifically, drop incidence was significantly lower in plots treated with Endura than in control plots for all crops except during fall 2006 and spring 2008 (Table 2 ). Drop incidence in plots treated with Contans was mostly comparable with Endura-treated plots and significantly lower than in control plots, with the exception of fall 2006 and spring 2008. The differences between three applications of Contans at either
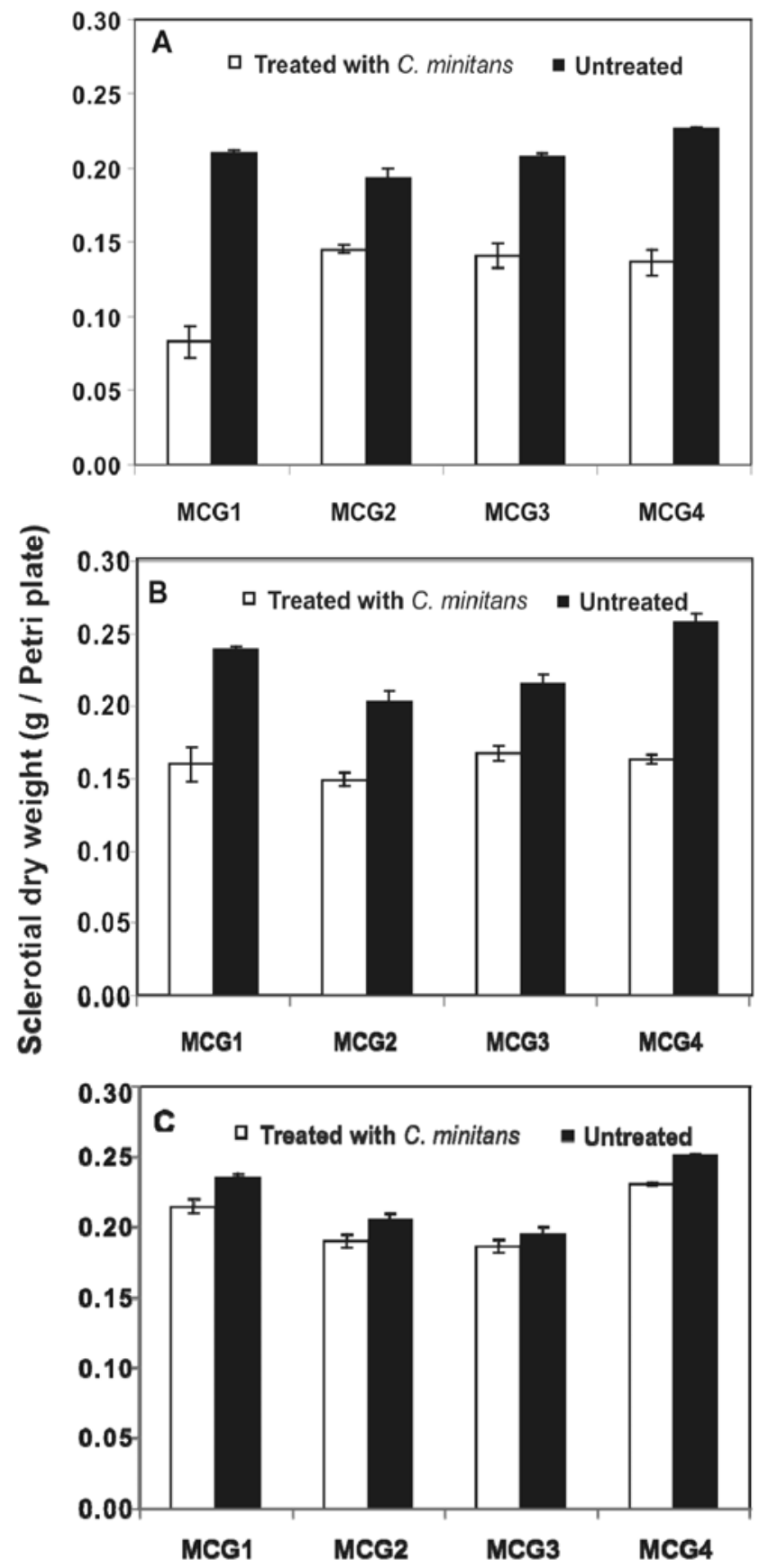

Mycelial Compatibility Groups

Fig. 1. Efficacy of Coniothyrium minitans against Sclerotinia minor in different mycelial compatibility groups (MCGs) at different growth phases in reducing sclerotial production. $C$. minitans inoculated at $\mathbf{A}$, mycelial phase; $\mathbf{B}$, early sclerotial formation phase; and $\mathbf{C}$, maturation phase.

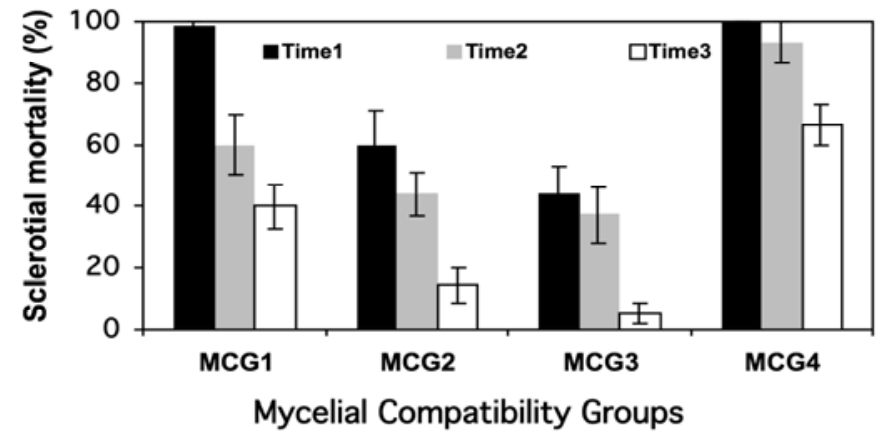

Fig. 2. Efficacy of Coniothyrium minitans against Sclerotinia minor in different mycelial compatibility groups (MCGs) at different growth phases in causing sclerotial mortality. Time 1, mycelial phase; Time 2, early sclerotial formation phase; and Time 3, sclerotial maturation phase.

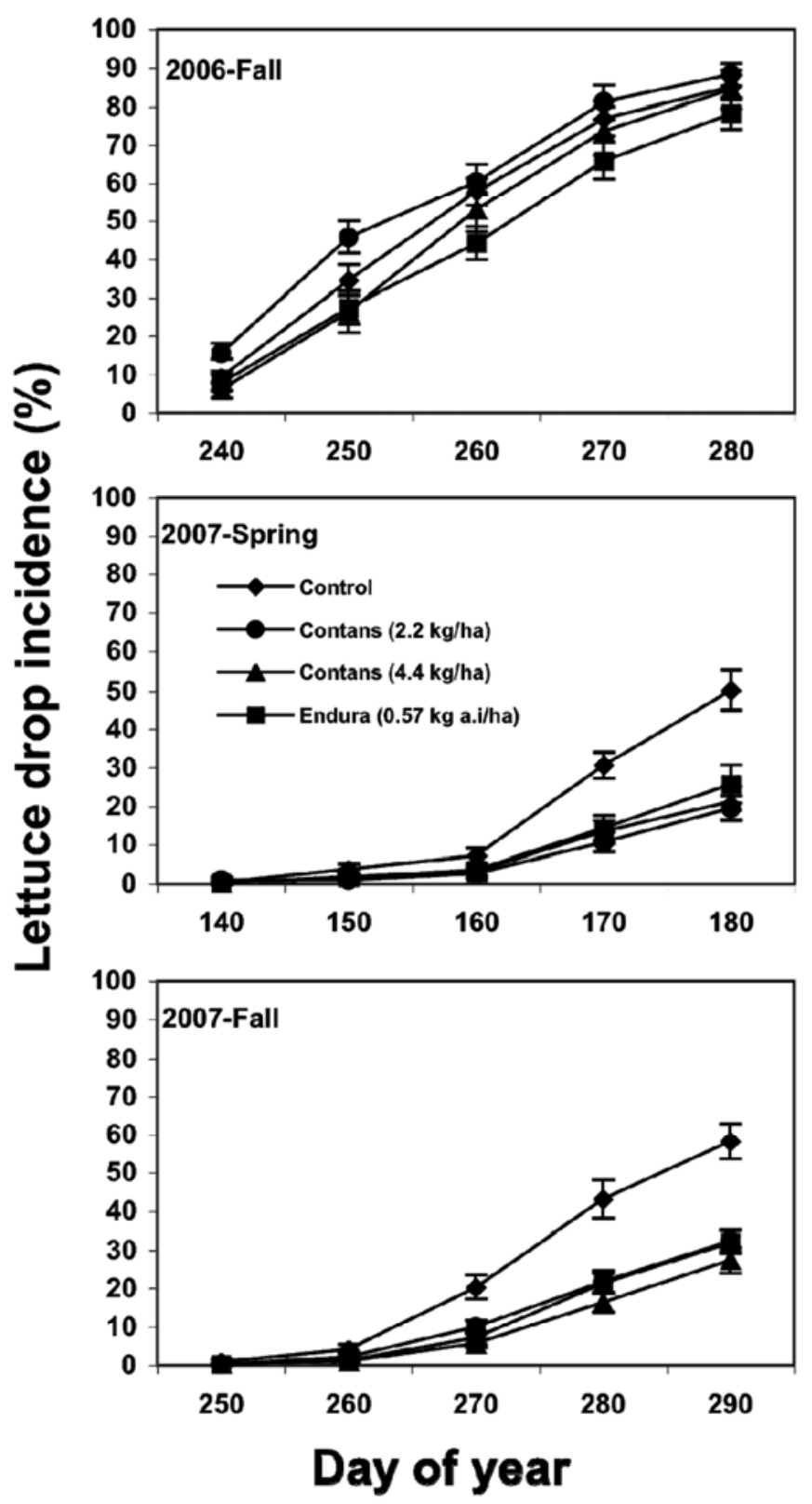

Fig. 3. Progress of lettuce drop in plots infested with Sclerotinia minor and treated either with different rates of Contans or with fungicide Endura in 2006 to 2007. Contans was applied three times, once at 1 week prior to thinning, once at post thinning, and once at postharvest before disking. Endura was applied twice, once immediately after thinning and once at 2 weeks post thinning. 
the 2.2 or $4.4 \mathrm{~kg} / \mathrm{ha}$ rate were insignificant during all cropping seasons. Likewise, there was no significant difference between the two and three applications of Contans (Table 2).

Similarly, the ANOVA on sclerotia population data showed significant effects of the year, season, and treatment, as well as the interactions of treatment-year and year-season (Table 3). The numbers of sclerotia increased from spring to fall 2007, and again significantly decreased for the subsequent spring crop for all the treatments. The numbers of sclerotia per $100 \mathrm{~cm}^{3}$ of soil was significantly lower in plots treated with Contans for all crops except during fall 2006, when the field was uniformly inoculated, and in fall 2007, when no significant difference was observed in drop incidence in the preceding spring crop (Table 4). The numbers of sclerotia in plots treated with Endura was comparable with and were statistically not significantly different from those in control plots (Table 4).

Effect of Contans and Endura on the relationship between sclerotial density and incidence of lettuce drop. There was a positive correlation between the number of sclerotia in each plot during a crop season and the percent disease incidence observed at the end of the crop season, and the relationship could be fitted well with a monomolecular model (Fig. 5). Nonlinear regression was significant, with the sum of squares predicted by model $=$ 49,540 and residual $=20,599, F=228.47$, and $P<0.0001$. The parameter estimate $b$ was also significant (95\% confidence interval was $0.0207 \pm 0.00179$ ). The ANOVA of the residuals showed significant effects of treatment, year, and interaction involving these two factors (Table 5). Specifically, in each crop, the treatment with the fungicide Endura had a significantly negative effect on the residuals while treatments with Contans $(2.2$ and $4.4 \mathrm{~kg}$ rates) did not have consistent effects (Table 6). Similarly, there was a positive correlation between final incidence in a crop and the numbers of sclerotia observed during the subsequent crop. This relationship for spring and fall crops could be fitted with two different linear models (Fig. 6). Both the correlation coefficient and the slope were higher for the trend line between the incidence in a spring crop and the inoculum level in the subsequent fall crop (S2) than for the trend line between incidence in a fall crop and inoculum level in the subsequent spring crop (S1) (Fig. 6). Similarly, significant effects of treatment and year, as well as inter-

TABLE 1. Analysis of variance for the fixed effect of year, cropping season, treatment, and their subsequent interactions on the final lettuce drop incidence

\begin{tabular}{|c|c|c|c|c|}
\hline \multirow[b]{2}{*}{ Variable } & \multicolumn{2}{|c|}{ Degrees of freedom $^{z}$} & \multirow[b]{2}{*}{$F$ value } & \multirow[b]{2}{*}{$P>F$} \\
\hline & Num & Den & & \\
\hline Year & 3 & 9 & 423.51 & $<0.0001$ \\
\hline Season & 1 & 9 & 22.92 & 0.0010 \\
\hline Year $\times$ season & 2 & 9 & 9.43 & 0.0062 \\
\hline Treatment & 5 & 87 & 17.29 & $<0.0001$ \\
\hline Year $\times$ treatment & 11 & 87 & 6.38 & $<0.0001$ \\
\hline Season $\times$ treatment & 5 & 87 & 1.74 & 0.1331 \\
\hline Year $\times$ season $\times$ treatment & 8 & 87 & 1.78 & 0.0918 \\
\hline
\end{tabular}

${ }^{\mathrm{z}} \mathrm{Num}=$ numerator and Den $=$ denominator.
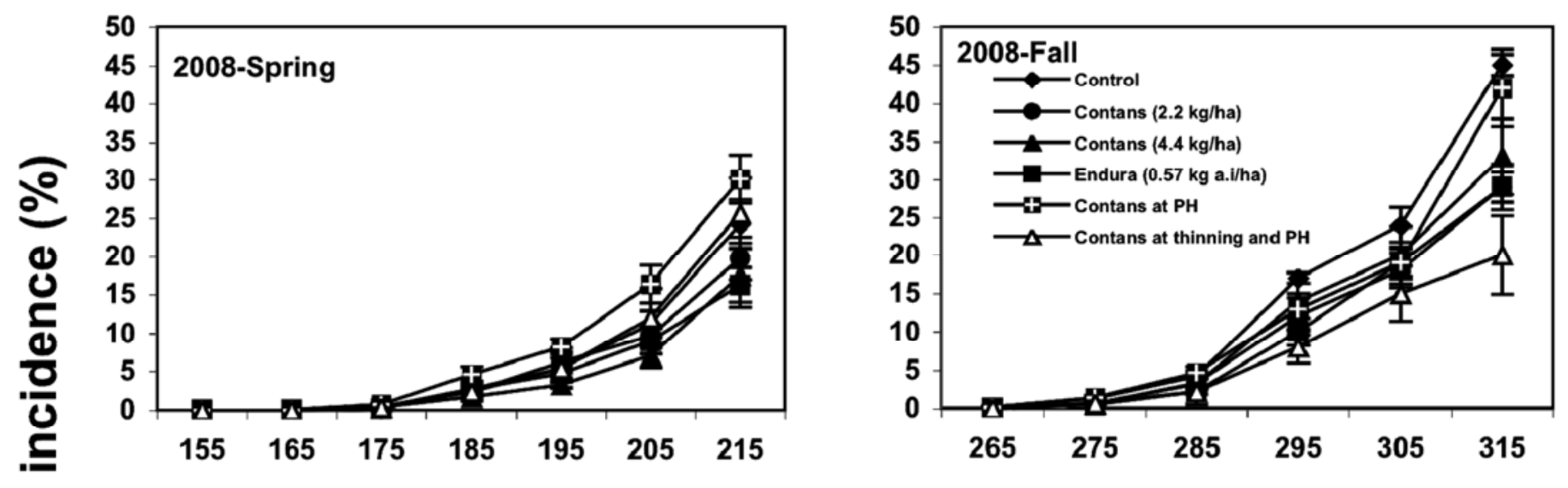

응
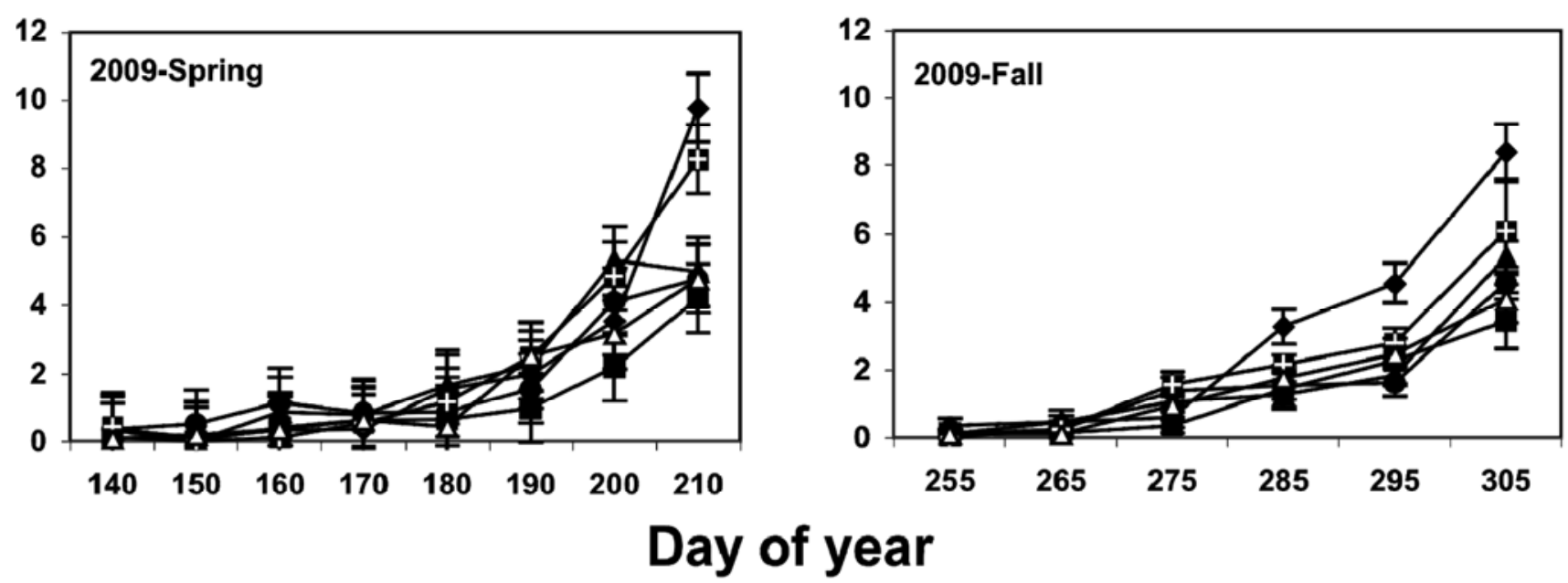

Fig. 4. Progress of lettuce drop in plots infested with Sclerotinia minor and treated either with different rates of Contans at different times (PH $=$ postharvest) or with the fungicide Endura in 2008 to 2009. Contans was applied three times unless otherwise stated: once at 1 week prior to thinning, once at post thinning, and once at postharvest before disking. Endura was applied twice, once immediately after thinning and once at 2 weeks post thinning. 
actions involving them, were detected on the model residuals (Table 6). The effects of Contans treatments were significantly negative for both rates in spring 2007 and for the $4.4 \mathrm{~kg} / \mathrm{ha}$ rate only in spring 2009 but not in other seasons (Table 6). Effects of Endura were mostly positive over all crops (Table 6).

\section{DISCUSSION}

Attempts to employ Contans, a commercial formulation of $C$. minitans against diseases caused by $S$. minor, had previously been unsuccessful (9). In this study, we explored the biological factors that may improve efficacy of Contans against $S$. minor in laboratory experiments and, subsequently, applied this knowledge for efficacious control of $S$. minor on lettuce under field conditions over multiple seasons. The laboratory studies determined the optimal time for enhancing interactions between the pathogen and the biocontrol agent to be the mycelial phase. This enhanced interaction at the mycelial phase could possibly be due to the absence of melanin in the mycelia (4). Melanin deposition occurs only during the sclerotial maturation phase that is believed to protect the sclerotia from adverse environmental conditions and microbial degradation (3). Based on the laboratory results, field applications of Contans were timed at post harvest to maximize the interactions between $C$. minitans and $S$. minor to reduce the inoculum returned to the soil after a susceptible crop, and at prethinning and post-thinning periods during the season to reduce potential infection. The efficacy of Contans on lettuce drop incidence was comparable with that of the standard fungicide treatment commonly used against $S$. minor in lettuce. Although the lower levels of lettuce drop in Contans treatments were correlated with significantly lower levels of sclerotia, the lower levels of lettuce drop despite the presence of higher inoculum in the Endura treatment was attributable to the prevention of infection by $S$. minor. Thus, the Contans treatment has the potential for reclamation of soil highly infested with the sclerotia of $S$. minor and, over the longer term, is a much more sustainable treatment against this pathogen than the application of fungicides.

Contans consistently outperformed fungicides in controlling lettuce drop caused by S. sclerotiorum (9). Prior studies (9) had determined that the efficacy of Contans against $S$. minor was low when applied at post thinning, similar to the standard fungicide application (27). The altered timing of application as demonstrated in this study at the recommended rate of Contans (2.2 $\mathrm{kg} / \mathrm{ha}$ ) rendered it equally effective against $S$. minor. However, significant lettuce drop suppression was attained only from the second crop because the soil was infested with laboratory-produced sclerotial inoculum in 2006. Generally, sclerotia produced under controlled and nutrient-surplus conditions are more efficient in causing the disease than those produced under natural field conditions (40). A single sclerotium located within the competence volume (soil encompassing the maximum depth and a distance from which sclerotium can infect lettuce plant) is sufficient to cause disease (23). The application of a high density of sclerotial inoculum in 2006 resulted in the highest disease incidence of all the seasons despite the various treatments. $C$. minitans is a slow-growing fungus (41); therefore, parasitizing $S$. minor sclerotia by $C$. minitans in field soil is also expected to be slow. In addition, it is evident from our laboratory studies that sclerotia that are partially parasitized by $C$. minitans could still germinate and produce mycelia that can infect plants (data not shown). It is possible that $C$. minitans could have initiated the parasitism of sclerotia during the very first season but, before completion of this process, plants may have been infected by the rapid growth of mycelia from germinated $S$. minor sclerotia (46).

Despite the higher lettuce drop incidence in fall 2006, sclerotial population during the 2007 spring season was significantly low in Contans-treated plots. Under optimal conditions, sclerotia germinate eruptively, producing masses of hyphae that come in contact with lettuce roots, crowns, and senescent leaves, causing soft watery root, crown, and head rot. Nearly the entire host biomass (both above- and belowground) is converted to pathogen biomass, and the large numbers of sclerotia produced from colonized lettuce tissues are released into the soil and serve as inoculum for subsequent crops (39). Therefore, the success of a biocontrol agent would be measured by its ability to prevent this massive conversion of the host biomass into pathogen biomass and the resultant soil inoculum augmentation. At harvest, many diseased lettuce heads that are infected during late growth stage are covered with $S$. minor mycelia and few mature sclerotia. Application of Contans over crop residue at this stage not only facilitates greater interaction of $C$. minitans with the most susceptible stage of $S$. minor but also provides sufficient time for $C$. minitans to successfully parasitize both the mycelia and sclerotia before the next crop. The consistently greater reduction in the number of

TABLE 3. Analysis of variance for the fixed effect of year, cropping season, treatment, and their subsequent interactions on sclerotia population

\begin{tabular}{|c|c|c|c|c|}
\hline \multirow[b]{2}{*}{ Variable } & \multicolumn{2}{|c|}{ Degrees of freedom ${ }^{z}$} & \multirow[b]{2}{*}{$F$ value } & \multirow[b]{2}{*}{$P>F$} \\
\hline & Num & Den & & \\
\hline Year & 2 & 6 & 174.13 & $<0.0001$ \\
\hline Season & 1 & 9 & 38.07 & 0.0002 \\
\hline Year $\times$ season & 2 & 9 & 50.56 & $<0.0001$ \\
\hline Treatment & 5 & 78 & 16.76 & $<0.0001$ \\
\hline Year $\times$ treatment & 8 & 78 & 5.96 & $<0.0001$ \\
\hline Season $\times$ treatment & 5 & 78 & 0.24 & 0.9411 \\
\hline Year $\times$ season $\times$ treatment & 8 & 78 & 0.42 & 0.9032 \\
\hline
\end{tabular}

$\mathrm{z}$ Num $=$ numerator and Den $=$ denominator.

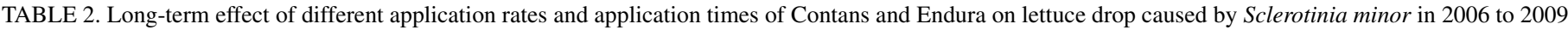

\begin{tabular}{|c|c|c|c|c|c|c|c|}
\hline \multirow[b]{3}{*}{ Treatments } & \multicolumn{7}{|c|}{ Lettuce drop incidence at the end of the crop season $(\%)^{\mathrm{v}}$} \\
\hline & \multirow[b]{2}{*}{2006} & \multicolumn{2}{|c|}{2007} & \multicolumn{2}{|c|}{2008} & \multicolumn{2}{|c|}{2009} \\
\hline & & Spring & Fall & Spring & Fall & Spring & Fall \\
\hline Contans $2.2 \mathrm{~kg} / \mathrm{ha}^{\mathrm{w}}$ & a $88.4 \mathrm{a}$ & c $19.6 \mathrm{~b}$ & b $32.4 \mathrm{~b}$ & c $19.7 \mathrm{bc}$ & bc $29.0 \mathrm{dc}$ & $\mathrm{d} 5.0 \mathrm{~b}$ & d $5.0 \mathrm{~b}$ \\
\hline Contans $4.4 \mathrm{~kg} / \mathrm{ha}^{\mathrm{w}}$ & a $84.5 \mathrm{ab}$ & bc $21.3 \mathrm{~b}$ & bc $27.4 \mathrm{~b}$ & $\operatorname{cd} 17.5 \mathrm{c}$ & b 33.0 bc & $\mathrm{d} 5.0 \mathrm{~b}$ & d $5.3 \mathrm{~b}$ \\
\hline Contans $2.2 \mathrm{~kg} / \mathrm{ha}^{\mathrm{x}}$ & $\ldots$ & $\ldots$ & $\ldots$ & b 30.2 a & a $42.0 \mathrm{ab}$ & c $8.3 \mathrm{a}$ & c $6.1 \mathrm{~b}$ \\
\hline Contans $2.2 \mathrm{~kg} / \mathrm{ha}^{\mathrm{y}}$ & $\ldots$ & $\ldots$ & $\ldots$ & a $25.7 \mathrm{ab}$ & a $20.0 \mathrm{~d}$ & b $5.0 \mathrm{~b}$ & b $4.1 \mathrm{~b}$ \\
\hline Endura $0.57 \mathrm{~kg} / \mathrm{ha}^{\mathrm{z}}$ & a $78.2 \mathrm{~b}$ & bc $25.7 \mathrm{~b}$ & b $32.0 \mathrm{~b}$ & $\operatorname{cd} 16.2 \mathrm{c}$ & bc $26.0 \mathrm{dc}$ & $\mathrm{d} 4.0 \mathrm{~b}$ & d $3.4 b$ \\
\hline Unsprayed control & a $85.0 \mathrm{ab}$ & bc $50.1 \mathrm{a}$ & b 58.4 a & d $24.2 \mathrm{abc}$ & $\mathrm{c} 45.0 \mathrm{a}$ & e $10.0 \mathrm{a}$ & e $8.4 \mathrm{a}$ \\
\hline
\end{tabular}

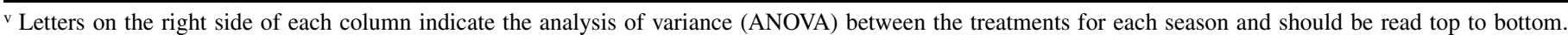
Letters on the left side of the each column indicate the ANOVA between the seasons for each treatment and should be read left to right. Columns with different letters are significantly different according to Holm-Sidak method $(P<0.05)$ based on the $F$ test in ANOVA.

${ }^{\mathrm{w}}$ Treatment consisted of three sprays, one at 1 week prior to thinning, one after thinning, and one before disking the first crop.

${ }^{x}$ Treatment consisted of one spray at postharvest.

y Treatment consisted of two sprays, one at post thinning and one at postharvest.

${ }^{\mathrm{z}}$ Fungicide Endura was applied twice, one after thinning and one at 2 weeks post thinning. 


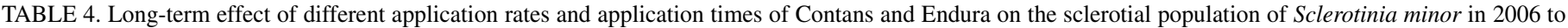
2009

\begin{tabular}{|c|c|c|c|c|c|c|c|}
\hline \multirow[b]{3}{*}{ Treatments } & \multicolumn{7}{|c|}{ Sclerotia population (no. of sclerotia/100 $\mathrm{cm}^{3}$ of soil) ${ }^{\mathrm{u}}$} \\
\hline & \multirow[b]{2}{*}{$2006^{\mathrm{v}}$} & \multicolumn{2}{|c|}{2007} & \multicolumn{2}{|c|}{2008} & \multicolumn{2}{|c|}{2009} \\
\hline & & Spring & Fall & Spring & Fall & Spring & Fall \\
\hline Contans $2.2 \mathrm{~kg} / \mathrm{ha}^{\mathrm{w}}$ & a 15.0 & b $4.9 \mathrm{~b}$ & a $23.1 \mathrm{bc}$ & b $4.4 \mathrm{~b}$ & b $2.0 \mathrm{c}$ & b $1.3 \mathrm{~b}$ & b $1.8 \mathrm{~d}$ \\
\hline Contans $4.4 \mathrm{~kg} / \mathrm{ha}^{\mathrm{w}}$ & a 15.0 & b $6.3 \mathrm{~b}$ & a $20.5 \mathrm{c}$ & b $4.8 \mathrm{~b}$ & b $4.0 \mathrm{bc}$ & b $1.6 \mathrm{~b}$ & b $2.1 \mathrm{dc}$ \\
\hline Contans $2.2 \mathrm{~kg} / \mathrm{ha}^{\mathrm{x}}$ & $\ldots$ & $\ldots$ & $\ldots$ & a $5.3 \mathrm{~b}$ & a $5.1 \mathrm{ab}$ & a $3.4 \mathrm{~b}$ & a $1.8 \mathrm{~d}$ \\
\hline Contans $2.2 \mathrm{~kg} / \mathrm{ha}^{\mathrm{y}}$ & $\ldots$ & $\ldots$ & $\ldots$ & a $3.9 \mathrm{~b}$ & a $5.7 \mathrm{ab}$ & a $3.5 \mathrm{~b}$ & a $3.0 \mathrm{bc}$ \\
\hline Endura $0.57 \mathrm{~kg} / \mathrm{ha}^{\mathrm{z}}$ & bc 15.0 & b $22.3 \mathrm{a}$ & a 40.1 a & $\mathrm{cd} 8.9 \mathrm{a}$ & $\mathrm{cd} 6.7 \mathrm{a}$ & $\operatorname{cd} 7.3 \mathrm{a}$ & d $3.4 \mathrm{ab}$ \\
\hline Unsprayed control & bc 15.0 & b 19.8 a & a $39.2 \mathrm{ab}$ & $\mathrm{cd} 7.6 \mathrm{a}$ & $\operatorname{cd} 7.1 \mathrm{a}$ & $\operatorname{cd} 7.2 \mathrm{a}$ & $\mathrm{d} 4.2 \mathrm{a}$ \\
\hline
\end{tabular}

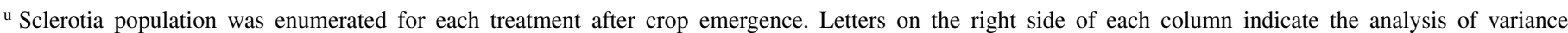
(ANOVA) between the treatments for each season and it should be read top to bottom. Letters on the left side of the each column indicate the ANOVA between the season for each treatment and should be read left to right. Columns with different letters are significantly different according to Holm-Sidak method $(P<$ 0.05 ) based on the $F$ test in ANOVA.

v Sclerotial estimates was derived from the number of sclerotia originally placed into plots.

${ }^{\mathrm{w}}$ Treatment consisted of three sprays, one at 1 week prior to thinning, one at after thinning, and one at postharvest before disking.

$\mathrm{x}$ Treatment consisted of one spray at postharvest.

$\mathrm{y}$ Treatment consisted of sprays at thinning and at postharvest.

${ }^{\mathrm{z}}$ Fungicide Endura was applied twice, once immediately after thinning and another at 2 weeks post thinning.

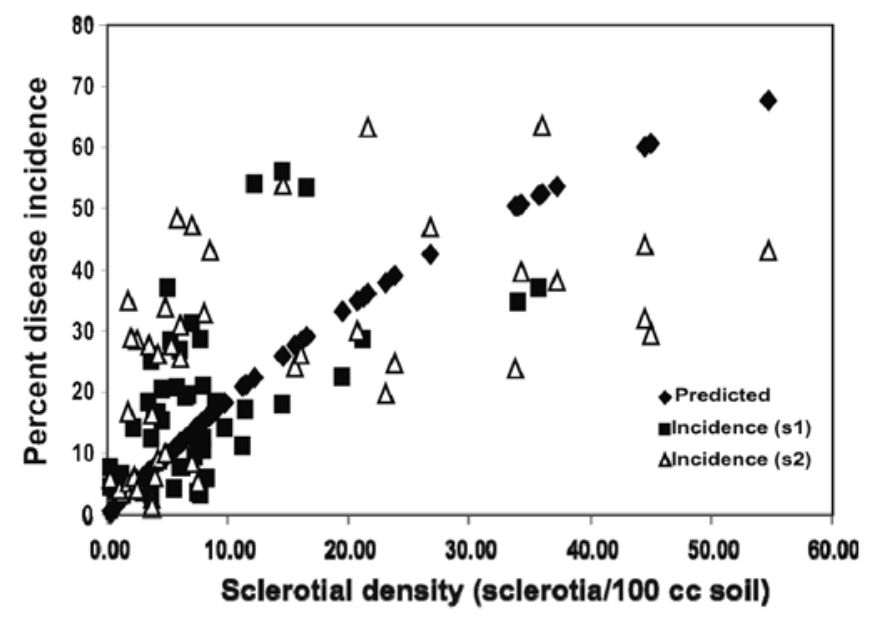

Fig. 5. Relationship between sclerotium density and lettuce drop incidence observed within a single crop season. $\mathrm{S} 1=$ spring season and $\mathrm{S} 2=$ fall season.

viable sclerotia at the beginning of the spring season could also have been caused by the greater time elapsed between the fall and spring crops that facilitated the parasiticism of $C$. minitans to $S$. minor sclerotia relative to the reductions observed between the spring and fall crops. Even though there was a general decline in number of soilborne sclerotia in all treatments between fall and spring crops, treatment differences were large and significant. The reductions in Contans-treated plots were significantly greater than in untreated control or Endura-treated plots. Additional applications at 1 week prior to and 1 week following thinning may serve to further increase the colonization of mycelia from germinating sclerotia and reduce infection of lettuce plants.

This study also revealed that a higher rate of Contans $(4.4 \mathrm{~kg} / \mathrm{ha})$ did not result in concomitant decreases in lettuce drop incidence. The lack of increased efficacy with increased rate of application of Contans is consistent with a previous report (33). Together, these results revealed that the application timing of this biocontrol product is more critical than the higher rate of application to manage lettuce drop in the field. Consistent application of Contans over several seasons to the same field facilitates augmentation of soil populations of $C$. minitans and provides increased opportunities for $C$. minitans to interact with various growth stages of sclerotia over several crop seasons. In all likelihood, this resulted in significant reductions of sclerotial population and subsequent reduction of lettuce drop in the Contans treatments over the course of this study.
TABLE 5. Analysis of variance for the fixed effect of year, cropping season, treatment, and their subsequent interactions on the residue calculated as the difference between predicted and observed incidence

\begin{tabular}{|c|c|c|c|c|}
\hline \multirow[b]{2}{*}{ Variable } & \multicolumn{2}{|c|}{ Degrees of freedom ${ }^{\mathrm{z}}$} & \multirow[b]{2}{*}{$F$ value } & \multirow[b]{2}{*}{$P>F$} \\
\hline & Num & Den & & \\
\hline Year & 2 & 6 & 48.61 & 0.0002 \\
\hline Season & 1 & 9 & 0.79 & 0.3963 \\
\hline Year $\times$ season & 2 & 9 & 32.84 & $<0.0001$ \\
\hline Treatment & 3 & 54 & 18.5 & $<0.0001$ \\
\hline Year $\times$ treatment & 6 & 54 & 3.46 & 0.0058 \\
\hline Season $\times$ treatment & 3 & 54 & 0.79 & 0.5038 \\
\hline Year $\times$ season $\times$ treatment & 6 & 54 & 0.24 & 0.9605 \\
\hline
\end{tabular}

$\mathrm{z}$ Num $=$ numerator and Den $=$ denominator

Contans may not be equally effective against all populations of $S$. minor, as demonstrated by the differential efficacy against strains from different MCGs. An evaluation of the mycelial compatibility group to which a field isolate belongs would be necessary before a blanket application of this product to manage diseases caused by $S$. minor is made. The reasons for the differential interaction of $C$. minitans with different MCGs of S. minor are unclear. The role of melanin (3) and oxalic acid (12) in protection against antagonist microbes has previously been shown in many fungi, and the level of oxalic acid secretion among $S$. sclerotiorum isolates from different hosts is variable (10). Thus, differences in the amount of oxalic acid and melanin secretion in different MCGs could possibly determine their susceptibility by $C$. minitans. However, the increased efficacy of $C$. minitans at the mycelial stage as demonstrated in this study, and the absence of melanin in the mycelia of $S$. sclerotiorum (4) excluded the potential role of melanin in the differential interaction of the MCGs. Likewise, the possible role of oxalic acid for the differential interaction could also be excluded because oxalic acid from $S$. sclerotiorum was not inhibitory to the growth of C. minitans (14). Although efficacy of C. minitans against $S$. sclerotiorum has been demonstrated in many cropping systems on a commercial scale $(6,9,33)$, the molecular and biochemical basis of interactions between these two fungi is a relatively unexplored area (43). Now that the studies reported in this article have demonstrated methods to expand the efficacy of $C$. minitans against $S$. minor also, an exploration of these interactions at the biochemical, cellular, and molecular levels would undoubtedly contribute to other novel applications of this mycoparasite.

Results from the unsprayed infested control and the fungicide treatments revealed that, despite the initial infestation levels, sclerotial densities in soil are stabilized over time, as is the 
TABLE 6. Effects of different treatments on both sclerotial and incidence residuals estimated on theoretical model ${ }^{\mathrm{x}}$

\begin{tabular}{|c|c|c|c|c|c|c|}
\hline \multirow[b]{2}{*}{ Treatments } & \multicolumn{2}{|c|}{2007} & \multicolumn{2}{|c|}{2008} & \multicolumn{2}{|c|}{2009} \\
\hline & First crop & Second crop & First crop & Second crop & First crop & Second crop \\
\hline \multicolumn{7}{|l|}{ Effects on incidence $y$} \\
\hline Unsprayed control & A & A & A & A & $\mathrm{B}$ & A \\
\hline Contans $2.2 \mathrm{~kg} / \mathrm{ha}$ & $\mathrm{AB}$ & $\mathrm{A}$ & A & $\mathrm{AB}$ & A & A \\
\hline Contans $4.4 \mathrm{~kg} / \mathrm{ha}$ & $\mathrm{AB}$ & A & A & $\mathrm{AB}$ & A & A \\
\hline Endura $0.57 \mathrm{~kg} / \mathrm{ha}$ & $\mathrm{B}$ & $\mathrm{B}$ & $\mathrm{B}$ & $\mathrm{B}$ & $\mathrm{C}$ & $\mathrm{B}$ \\
\hline \multicolumn{7}{|c|}{ Effects on sclerotial population ${ }^{\mathrm{z}}$} \\
\hline Unsprayed control & A & $\mathrm{B}$ & $\mathrm{B}$ & $\mathrm{AB}$ & $\mathrm{AB}$ & $\mathrm{B}$ \\
\hline Contans $2.2 \mathrm{~kg} / \mathrm{ha}$ & $\mathrm{B}$ & $\mathrm{B}$ & $\mathrm{B}$ & $\mathrm{B}$ & $\mathrm{BC}$ & $\mathrm{AB}$ \\
\hline Contans $4.4 \mathrm{~kg} / \mathrm{ha}$ & B & $\mathrm{B}$ & B & $\mathrm{AB}$ & $\mathrm{C}$ & $\mathrm{AB}$ \\
\hline Endura $0.57 \mathrm{~kg} / \mathrm{ha}$ & A & A & A & A & A & A \\
\hline
\end{tabular}

${ }^{x}$ Columns with different letters are significantly different $(P<0.05)$ based on the $F$ test in analysis of variance.

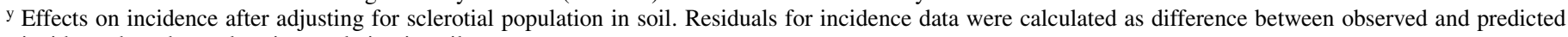
incidence based on sclerotia population in soil.

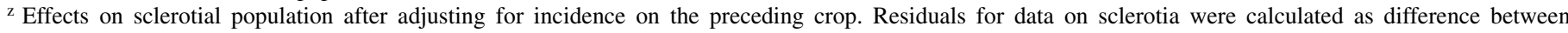
observed and predicted sclerotial population based on lettuce drop incidence in the preceding crop.

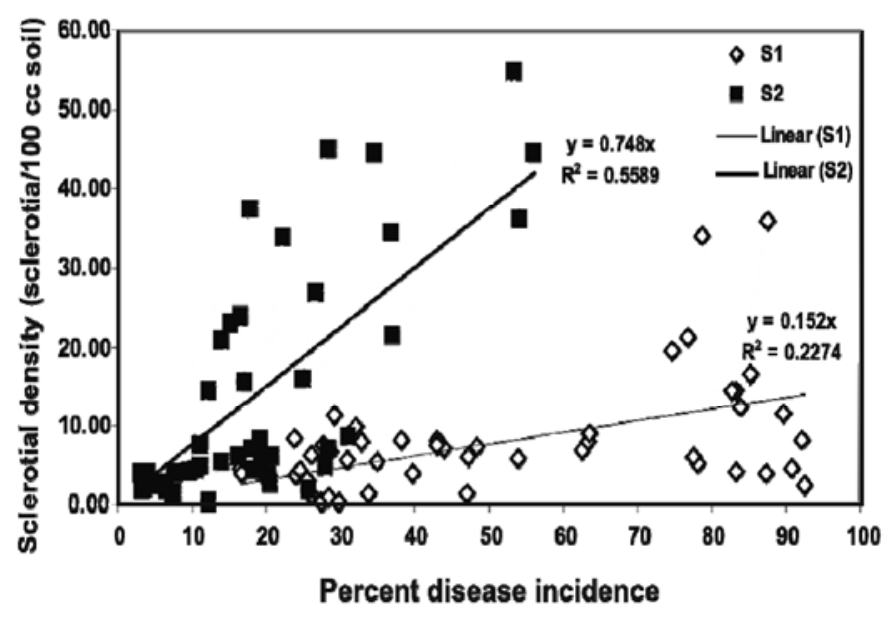

Fig. 6. Relationship between lettuce drop incidence and sclerotium density observed in subsequent lettuce seasons. $\mathrm{S} 1=$ spring season and $\mathrm{S} 2=$ fall season.

incidence of lettuce drop in a field. In these two treatments, even though the number of sclerotia increased significantly within a crop season, increases were not sustained over the years. On average, there was a $25 \%$ reduction in the number of sclerotia from the end of a season to the beginning of the subsequent season. Two factors may have been responsible for this. First, tillage may have redistributed the sclerotia both horizontally and vertically, resulting in a dilution of the numbers of sclerotia added after an infected lettuce crop in the upper soil profile. Second, the between-season survival of sclerotia was likely low, and even lower from the end of a fall crop to the beginning of the subsequent spring crop. This period is much longer than from the end of spring crop to the fall crop, and coincides with the onset of the rainy season in coastal California. One possible explanation for the lower survival of sclerotia may be the increased microbial degradation of sclerotia in soil. Greater numbers of sclerotia of $S$. minor were infected by Sporidesmium sclerotivorum at higher water potentials but colonization and infection of sclerotia were limited when water potential was lower than $-3 \mathrm{MPa}$ (1). Another reasonable explanation could be that the tillage equipment that was used for all plots may have inadvertently introduced $C$. minitans from the Contans treatments into these two treatments and this, in turn, may have resulted in reductions in the numbers of sclerotia. Furthermore, sclerotia of several fungi, including Sclerotinia spp., leak copious pheromone-like chemicals under optimal moisture conditions, and these substances often have stimulatory effect on many soil microbes $(14,42)$. The large quantity of exudates leaked from the increased sclerotial popu- lation in the first few crop seasons might possibly have promoted the activities of microbial antagonists of sclerotia naturally present in soil which resulted in enhanced degradation of sclerotia.

In summary, the commercial formulation of $C$. minitans marketed as Contans was effective against lettuce drop caused by $S$. minor with the modified applications explored in this study. Application of Contans over lettuce crop residue before disking facilitates direct contact between $C$. minitans and the most susceptible mycelial stage of $S$. minor, and reduces sclerotial formation and soil augmentation of sclerotia. However, Contans was not equally effective against all the MCGs of $S$. minor; therefore, determining the susceptibility of the prevalent MCGs of particular production areas to $C$. minitans or at least determining MCGs of the field isolates is important before a blanket recommendation of Contans for lettuce drop management is made.

\section{ACKNOWLEDGMENTS}

P. Chitrampalam and B. M. Wu contributed equally to the work reported in this article and should be considered joint senior authors. This study was funded by grants from Prophyta, Inc., Germany, and a competitive grant awarded to K. Subbarao and B. M. Wu from the United States Department of Agriculture Western Regional IPM Program. We thank F. Hernandez, M. Orozco, R. Marchebout, K. Kammeijer, and P. Ayala for their laboratory assistance.

\section{LITERATURE CITED}

1. Adams, P. B., and Ayers, W. A. 1980. Factors affecting parasitic activity of Sporidesmium sclerotivorum on sclerotia of Sclerotinia minor in soil. Phytopathology 70:366-368.

2. Adams, P. B., and Fravel, D. R. 1990. Economical biological control of Sclerotinia lettuce drops by Sporidesmium sclerotivorum. Phytopathology 80:1120-1124.

3. Bell, A. A., and Wheeler, M. H. 1986. Biosynthesis and functions of fungal melanin. Annu. Rev. Phytopathol. 24:411-451.

4. Bolton, M. D., Thomma, B. P. H. J., and Nelson, B. D. 2006. Pathogen profile: Sclerotinia sclerotiorum (Lib.) de Bary, biology and molecular traits of a cosmopolitan pathogen. Mol. Plant Pathol. 7:1-16.

5. Borriss, H. 2009. Lettuce profile. Agricultural Marketing Resource Center, University of California.

6. Budge, S. P., and Whipps, J. M. 2001. Potential for integrated control of Sclerotinia sclerotiorum in glasshouse lettuce using Coniothyrium minitans and reduced fungicide application. Phytopathology 91:221-227.

7. Cassiolato, A. M. R., Baker, R., and Melo, I. S. D. 1997. Action of Trichoderma harzianum mutants on the formation and carpogenic germination of Sclerotinia sclerotiorum sclerotia and lettuce plant survival. Fitopatol. Bras. 22:34-38.

8. Castro, B. L. 1995. Antagonism of some isolates of Trichoderma koningii, originating in Colombian soils, against Rosellinia bunodes, Sclerotinia sclerotiorum and Pythium ultimum. Fitopatol. Colomb. 19:7-18.

9. Chitrampalam, P., Figuli, P. J., Matheron, M. E., Subbarao, K. V., and Pryor, B. M. 2008. Biocontrol of lettuce drop caused by Sclerotinia sclerotiorum and $S$. minor in desert agroecosystems. Plant Dis. 92:1625-1634. 
10. Druman, S. B., Menendez, A. B., and Godeas, A. M. 2005. Variation in oxalic acid production and mycelial compatibility within field population of Sclerotinia sclerotiorum. Soil Biol. Biochem. 37:2180-2184.

11. Elad, Y. 2000. Trichoderma harzianum T39 preparation for biocontrol of plant diseases-control of Botrytis cinerea, Sclerotinia sclerotiorum, and Cladosporium fulvum. Biocontrol Sci. Technol. 10:499-507.

12. Ghaffar, A. 1976. Inhibition of fungi as affected by oxalic acid production by Sclerotium delphinii. Pak. J. Bot. 86:69-73.

13. Giczey, G., Kerenyi, Z., Fulop, L., and Hornok, L. 2001. Expression of cmg1, and exo-beta-1,3-glucanase gene from Coniothyrium minitans, increases during sclerotial parasitism. Appl. Environ. Microbiol. 67:865871 .

14. Grendene, A., and Marciano, P. 1999. Interaction between Sclerotinia sclerotiorum and Coniothyrium minitans strains with different aggressiveness. Phytoparasitica 27:1-6.

15. Grogan, R. G., Sall, M. A., and Punja, Z. K. 1980. Concepts for modeling root infection by soilborne fungi. Phytopathology 70:361-363.

16. Hao, J. J., and Subbarao, K. V. 2003. Effects of broccoli rotation on lettuce drop caused by Sclerotinia minor and on the population density of sclerotia in soil. Plant Dis. 87:159-166.

17. Hao, J. J., and Subbarao, K. S. 2005. Comparative analyses of lettuce drop epidemics caused by Sclerotinia minor and S. sclerotiorum. Plant Dis. 89:717-725.

18. Hao, J. J., and Subbarao, K. V. 2006. Dynamics of lettuce drop incidence and Sclerotinia minor inoculum under varied crop rotations. Plant Dis. 90:269-278.

19. Hayes, R. J., Wu, B. M., Chitrampalam, P., Pryor, B. M., and Subbarao, K. V. 2010. Assessment of resistance in lettuce (Lactuca sativa L.) to mycelial and ascospore infection by Sclerotinia minor Jagger and $S$. sclerotiorum (Lib.) de Bary. Hortscience 45:333-341.

20. Huang, H., Erickson, R. S., and Huang, C. 2000. Soil treatment with fungal agents for control of apothecia of Sclerotinia sclerotiorum in bean and pea crops. Plant Pathol. Bull. 9:53-58.

21. Huang, H. C., Bremer, E., Hynes, R. K., and Erickson, R. S. 2000. Foliar application of fungal biocontrol agents for the control of white mold of dry bean caused by Sclerotinia sclerotiorum. Biol. Control 18:270-276.

22. Huang, H. C., and Hoes, J. A. 1976. Penetration and infection of Sclerotinia sclerotiorum by Coniothyrium minitans. Can. J. Plant Pathol. 3:219-222.

23. Imolehin, E. D., and Grogan, R. G. 1980. Factors affecting survival of sclerotia, and effects of inoculum density, relative position, and distance of sclerotia from the host on infection of lettuce by Sclerotinia minor. Phytopathology 70:1162-1167.

24. Inbar, J., Menendez, A., and Chet, I. 1996. Hyphal interaction between Trichoderma harzianum and Sclerotinia sclerotiorum and its role in biological control. Soil Biol. Biochem. 28:757-763.

25. Jackson, L. E., Mayberry, K., Laemmlen, F., Koike, S. T., Schulbach, K., and Chaney, W. 1996. Iceberg lettuce production in California. Univ. Calif. Div. Agric. Nat. Resour. Publ. 7215.

26. Jones, E. E., Mead, A., and Whipps, J. M. 2004. Effect of inoculum type and timing of application of Coniothyrium minitans on Sclerotinia sclerotiorum: Control of Sclerotinia disease in glasshouse lettuce. Plant Pathol. 53:611-620.

27. Klose, S., Wu, B. M., Ajwa, H. A., Koike, S. T., and Subbarao, K. V. 2010. Reduced efficacy of rovral and botran to control Sclerotinia minor in lettuce production in the Salinas Valley may be related to accelerated fungicide degradation in soil. Crop Prot. 29:751-756.

28. Li, G. Q., Huang, H. C., Acharya, S. N., and Ericson, R. S. 2005. Effectiveness of Coniothyrium minitans and Trichoderma atroviride in suppression of Sclerotinia blossom blight of alfalfa. Plant Pathol. 54:204211.

29. Matheron, M. E., and Matejka, J. C. 1989. Evaluation of new fungicides for the control of leaf drop of lettuce. J. Rio Grande Valley Hortic. Soc. 42:71-74.

30. Matheron, M. E., and Porchas, M. 2004. Activity of Boscolid, Fenhexamid, Fluazinam, Fludioxonil, and Vinclozolin on growth of Sclerotinia minor and S. sclerotiorum and development of lettuce drop. Plant Dis. 88:665-668.

31. McLean, K. L., and Stewart, A. 2000. Application strategies for control of onion white rot by fungal antagonists. N. Z. J. Crop Hortic. Sci. 28:115122.

32. Melzer, M. G., and Boland, G. J. 1994. Epidemiology of lettuce drop caused by Sclerotinia minor. Can. J. Plant Pathol. 16:170-176.

33. Partridge, D. E., Sutton, T. B., Jordan, D. L., Curtis, V. L., and Bailey, J. E. 2006. Management of Sclerotinia blight of peanut with the biological control agent Coniothyrium minitans. Plant Dis. 90:957-963.

34. Phillips, A. J. L., and Price, K. 1983. Structural aspects of the parasitism of sclerotia of Sclerotinia sclerotiorum (Lib.) de Bary by Coniothyrium minitans. Phytopathol. Z. 107:193-203.

35. Purdy, L. H. 1979. Sclerotinia sclerotiorum: history, diseases and symptomology, host range, geographic distribution and impact. Phytopathology 69:875-880.

36. Ridgway, H. J., Rabeendran, N., Eade, K., and Stewart, A. 2001. Application timing of Coniothyrium minitans A69 influences biocontrol of Sclerotinia minor in lettuce. Proc. Conf. Palmerston North, New Zealand. N. Z. Plant Prot. 54:14-16.

37. Subbarao, K. V. 1998. Progress toward integrated management of lettuce drop. Plant Dis. 82:1068-1078.

38. Subbarao, K. V., Dacuyan, S., Koike, S. T., and Jackson, L. E. 1994. Evaluation of three quantitative assays for Sclerotinia minor. Phytopathology 84:1471-1475.

39. Subbarao, K. V., Hubbard, J. C., and Schulbach, K. F. 1997. Comparison of lettuce disease and yield under subsurface drip and furrow irrigation. Phytopathology 87:877-883.

40. Trutmann, P., Keane, P. J., and Merriman, P. R. 1980. Reduction of sclerotial inoculum of Sclerotinia sclerotiorum with Coniothyrium minitans. Soil Biol. Biochem. 12:461-465.

41. Whipps, J. M., and Gerlagh, M. 1992. Screening of sclerotial mycoparasites of Sclerotinia sclerotiorum. Mycol. Res. 94:607-612.

42. Whipps, J. M., Grewal, S. K., and van der Goes, P. 1991. Interactions between Coniothyrium minitans and sclerotia. Mycol. Res. 95:295-299.

43. Whipps, J. M., Sreenivasaprasad, S., Muthumeenakshi, S., Roger, C. W., and Challen, M. P. 2008. Use of Coniothyrium minitans as a biological control agent and some molecular aspect of sclerotial mycoparasitism. Eur. J. Plant Pathol. 121:323-330.

44. Wu, B. M., and Subbarao, K. V. 2002. Sclerotial survival of S. minor and S. sclerotiorum in California. (Abstr.) Phytopathology 92:S88.

45. Wu, B. M., and Subbarao, K. V. 2006. Analyses of lettuce drop incidence and population structure of Sclerotinia sclerotiorum and $S$. minor. Phytopathology 96:1322-1329.

46. Wu, B. M., Subbarao, K. V. 2008. Nonlinear colony extension of Sclerotinia minor and S. sclerotiorum. Mycologia 100:902-910. 